\title{
Programa Mais Médicos no Estado de Santa Catarina: breve relato de experiências iniciais
}

\section{More Doctors Program in the State of Santa Catarina: brief account of early experiences.}

\section{Programa Más Médico en el Estado de Santa Catarina: breve recuento de las experiencias tempranas.}

Rita de Cássia Gabrielli SOUZA LIMA ${ }^{1}$

Carlos Alberto Severo GARCIA JR. ${ }^{2}$

Edilaine KERKOSKI ${ }^{3}$

Fabiola Hermes CHESANI ${ }^{4}$

RESUMO: No Programa Mais Médicos, a interiorização de faculdades de medicina e a inserção de médicos em áreas brasileiras socialmente vulneráveis, potencializando a aproximação entre formação e realidade da população, isto é, a integração ensino e serviços são duas dimensões priorizadas. O presente estudo objetivou apresentar aspectos históricos da criação do Programa e um breve relato dos movimentos iniciais de uma pesquisa estadual em andamento, na perspectiva de um informante chave. É um estudo social, qualitativo, de caráter exploratório, descritivo e compreensivo. $\mathrm{O}$ instrumento eleito para a coleta de dados foi a entrevista narrativa. A análise foi conduzida pela abordagem hermenêutico-dialética. Os resultados apontaram a categoria - Da intenção ao gesto: abraçando os inúmeros Brasis em defesa da garantia do direito universal à saúde. Observou-se que o Programa representa uma franca possibilidade de garantia de realização do direito à saúde em rincões sombrios, marginalizados pela ausência de médicos, bem como um projeto transformador efetivo em defesa de uma formação em medicina para a atenção básica, para o Sistema Único de Saúde de todos os brasileiros: a serviço do Brasil.

Palavras-chave: Atenção Primária à Saúde; Avaliação de Programas e Projetos de Saúde; Direito 1 - Professora do Mestrado em Saúde e Gestão do Trabalho

2 - Mestrado em Educação pela Universidade Federal de Santa Maria (2010), Apoiador Institucional da Fundação para o Desenvolvimento Científicio e Tecnológico em Saúde..

3 - Doutorado em Doutorado em Enfermagem -Área de Concentração pela Universidade Federal de Santa Catarina, (2013). Trabalha no Revista Brasileira de Tecnologias Sociais

4 - Doutorado em Educação Cientifica e Tecnológica pela Universidade Federal de Santa Catarina, Brasil(2014)

Professor Titular da Universidade do Vale do Itajaí , Brasil. 
à Saúde.

ABSTRACT: The More Doctors Program, the internalization of medical schools and the inclusion of Brazilian doctors in socially vulnerable areas, increasing rapprochement between training and reality of the population, this is, the integration and education services are prioritized two dimensions. This study aims to present historical aspects of the program's creation and a brief account of the initial moves of a state research in progress with a view to a key informant. Social studies, qualitative, exploratory, descriptive and comprehensive character. The chosen instrument for data collection was narrative interview. The analysis was conducted by the hermeneuticdialectic approach. The results showed the category of the intention to gesture embracing the many Brazils in defense of ensuring universal right to health. It was observed that the program is an large possibility of realizing the right to health security in dark far corners, marginalized by a lack of doctors, as well as an effective transformative project in support of a training in medicine for primary health care to the Unified Health System all Brazilians: the service of Brazil. Key words: Primary Health Care; Program Evaluation; Right to Health.

RESÚMEN: E1 Programa Más Médicos, la internalización de las escuelas de medicina y la inserción de los médicos en las áreas de Brasil socialmente vulnerables, para mejorar el acercamiento entre la formación y la realidad de la población, es decir, el ajuste entre los servicios de educación y salud tienen prioridad. Este estudio tuvo como objetivo presentar los aspectos históricos de la creación del Programa Más Médicos y una breve reseña de los movimientos iniciales de una investigación en curso con miras a un informante clave. Se trata de un estudio social, cualitativo, exploratório y descriptivo. El instrumento elegido para la recolección de datos fue la entrevista narrativa. El análisis fue realizado por el enfoque hermenéutico-dialéctico. Los resultados mostraron la categoria - De la Intención y gesto, abrazando los muchos Brasiles en defensa de garantizar el derecho universal a la salud. Se observó que el Programa es una posibilidad abierta de la realización del derecho a la seguridad sanitaria en las regiones remotas marginados por la falta de médicos, así como un proyecto de transformación efectiva en apoyo de la formación en medicina de atención primaria de salud en el Sistema de Salud para todos los brasileños: el servicio de Brasil.

Palabras clave: Atención Primaria de Salud; Derecho a la Salud; Evaluación de Programas y Proyectos de Salud.

\section{INTRODUÇÃO}

Ao longo da década de 1990, o Ministério da Saúde brasileiro experimentou várias iniciativas operacionais e estratégicas em prol da consolidação do direito universal à saúde, garantido pela Constituição Cidadã, de $1988^{1}$. 
Em um cenário de dificuldades imputadas ao processo de descentralização, um grupo de secretários solicitou apoio financeiro ao Ministério da Saúde para a execução da Atenção Básica. Esta solicitação levou o Ministro da Saúde, em exercício, em 1993, a convocar uma reunião com secretários municipais, técnicos, consultores internacionais e especialistas para discutir as limitações e fragilidades vividas pelas gestões municipais na luta para a operacionalização da Atenção Básica². Nascia, naquele encontro, o Programa Saúde da Família (PSF). Consolidado no plano jurídico no ano seguinte, o PSF carregava o reconhecimento da necessidade de as gestões municipais trilharem caminhos capazes de transformar as históricas desigualdades em saúde em direito à saúde, usufruído, em âmbito municipal.

Após doze anos da sua regulamentação jurídica, o PSF consolidou-se como principal "estratégia para reorganização da Atenção Básica"’3. Foi transformado em uma política de Estado: a Política Nacional de Atenção Básica (PNAB) ${ }^{4}$. Primeiramente, através da Portaria $n^{0}$ 648, de março de 2006 aprovando diretrizes e normas para a organização da atenção básica para o PSF e Programa de Agentes Comunitário de Saúde (PACS) ${ }^{5}$. Posteriormente, a partir da Portaria $n^{0} 2.488$, tem a concepção revisada e atualizada em 2011 para Estratégia de Saúde da Família (ESF)³.

Um dos desafios mais expoentes do arcabouço teórico desta Política foi o de superar os históricos modelos assistencialistas e estruturar um modelo de atenção integral ${ }^{6}$. Um modelo articulado a partir de um conjunto de tecnologias físicas e humanas, visando à garantia das necessidades de saúde das comunidades. Sua realização requer deliberações, em que concorre uma pluralidade de saberes, fazeres, ferramentas, poderes, e estratégias políticas, por parte dos atores sociais. Dentre os atores sociais, o médico, de preferência especialista em medicina de família e comunidade, tem um papel fundamental.

O Brasil adentrou o século XXI com ampla expansão da cobertura de equipes de saúde da família. No entanto, não têm sido poucas as dificuldades encontradas pelos gestores municipais para a fixação de médicos na ESF, em municípios urbanos e áreas rurais ${ }^{6}$. Estudos apontam várias razões para este vazio, cabendo citar: a) as crescentes especializações ${ }^{7}$; b) o déficit formativo com base em um modelo de atenção centrado no cuidado, bem como a expressiva rotatividade de médicos em algumas localidades e escassez em outras devido, dentre outras, às dificuldades para atuar como médico generalista e ausência de uma rede de atenção densa e comprometida ${ }^{8-10}$; c) a insatisfação pelas atividades na Atenção Básica por ausência de condições materiais ${ }^{9}$; e d) expressiva interferência política nas ações e serviços prestados ${ }^{6}$.

Pesquisa realizada por Carvalho e Sousa (2013, p. 924) sobre a escassez de formação médica para o Sistema Único de Saúde (SUS), analisou o Programa de Valorização da Atenção Básica (PROVAB), instituído pelo governo federal em 2011. Os resultados sinalizaram a necessidade de uma "agenda propositiva" dialógica para a formação e para o trabalho na Atenção Básica, por parte do Estado brasileiro ${ }^{8}$. 
As autoras citam um estudo no qual os autores, ao analisaram o déficit de profissionais da Atenção Básica, com base no método Full Time Equivalent (FTE), observaram que as regiões mais desprovidas de médicos são aquelas em que há uma alta taxa de mortalidade infantil e utilização do Programa Bolsa Família ${ }^{8}$. Em outras palavras, os Brasis mais adoecidos e com menos condições de oportunidade para realizar o direito à saúde são os Brasis mais carentes de médicos na Atenção Básica. Nesse sentido, os infindáveis Brasis, relegados à margem do apregoado desenvolvimento vêm enfrentando efeitos perversos gerados pela desigualdade de distribuição de médicos na Atenção Básica, nos estados federativos e, no âmbito interestadual, gerados pela desigualdade distributiva entre municípios prósperos e municípios com alto índice de vulnerabilidade social.

Em decorrência deste cenário nacional, ocorreu um novo movimento a Brasília, em janeiro de 2013, similar em seu objeto, ao movimento realizado em 1993: condições para a garantia do direito à saúde das coletividades, em seus territórios vivos de produção de saúde. Vários prefeitos realizaram uma marcha simbólica à capital, em busca de saídas para suas necessidades imediatas de provimento de médicos. Dirigiram-se à Presidenta Dilma Rousseff e relataram suas dificuldades para a contratação desses profissionais, sobretudo nos municípios do interior e nas periferias ${ }^{11}$.

Desafiando a resistência de entidades médicas, a Presidenta editou uma Medida Provisória ( $\mathrm{n}^{\mathrm{o}}$ 621, de 8 de julho de 2013) não somente contemplando o provimento emergencial para os municípios, mas também ampliando as oportunidades de formação médica no Brasil. No primeiro momento, um Edital do Ministério da Saúde priorizou o eixo do provimento médico, incentivando a participação de médicos formados no Brasil. Em seguida, privilegiou brasileiros com diplomas no exterior e, posteriormente estrangeiros (intercambistas e cooperados). Novos profissionais começaram a chegar, em municípios solicitantes, em agosto de 2013. Em outubro do mesmo ano, o Congresso Nacional aprovou e a Presidente sancionou a Lei $n^{\circ} .12 .871$ conhecida como a Lei dos "Mais Médicos"12.

Uma vez sancionada a Lei, o Ministério da Educação e Cultura (MEC) lançou Edital, para fins de chamamento de Instituições de Ensino Superior (IES), com o objetivo de ampliar a oferta na graduação e residência médica no Brasil, além de lançar uma proposta de mudança no eixo dos locais de formação e uma reorientação da formação médica. Assim, na parceria interministerial entre Ministério da Saúde e MEC abriu-se outra oportunidade para que municípios localizados em regiões vulneráveis solicitassem mais médicos. As regiões foram definidas em função de um conjunto de critérios: áreas com percentual elevado de população em extrema pobreza, baixo índice de desenvolvimento humano ou regiões muito pobres, semiárido e região amazônica, áreas com população indígena e quilombola, locais com grande dificuldade de atrair e fixar profissionais, entre outros ${ }^{12}$.

Apesar da importância dos recursos humanos para o acesso à saúde, e das políticas anteriores do governo brasileiro para enfrentar as desigualdades na distribuição de médicos e o fortalecimento da atenção básica, nenhuma teve a abrangência, magnitude e celeridade do Programa Mais Médicos, 
inclusive na sua preocupação com a necessidade de mudança da formação médica ${ }^{13}$.

Deste modo, a partir de uma ação conjunta entre o Ministério da Saúde e o MEC foram disparados investimentos em duas dimensões cruciais de infraestrutura dos serviços na Atenção Básica: na formação de um maior contingente de profissionais médicos e na inserção de médicos em áreas brasileiras socialmente vulneráveis, potencializando a aproximação entre formação e realidade da população, isto é, a integração ensino e serviços ${ }^{12}$. Um exemplo desse esforço é a Portaria Interministerial $\mathrm{n}^{\mathrm{o}} 1.369$, de julho de 2013, que dispõe sobre a implementação do Projeto Mais Médicos para o Brasil ${ }^{14}$.

O Brasil possui 5570 municípios em sua extensão territorial e uma população de 202.799 .518 habitantes. Está dividido em 27 unidades federativas, sendo 26 Estados e um Distrito Federal. A diversidade cultural, econômica, social e geográfica é imensa; do mesmo modo, a informação em saúde é um instrumento de saúde pública que desde o início do século XX tem valor e representa a diversidade no campo da saúde. O Estado de Santa Catarina pertence a Região Sul do Brasil, composta pelos Estados do Paraná, Santa Catarina e Rio Grande do Sul. Ao todo, são 295 municípios no Estado, com capital sendo Florianópolis, segundo município mais populoso e localizado no litoral. Santa Catarina conta com uma população de 6.727.148 habitantes. Deste universo populacional, 16.041 (0,24\%) são de população indígena, 183.857 (2,73\%) preta, 26.017 (0,39\%) amarela, $775.558(11,53 \%)$ parda e $5.246 .868(85,11 \%)$ branca, sendo esta a predominante ${ }^{15}$.

Com base nos dados do Ministério do Desenvolvimento Social e Combate à Fome (MDS), entre os 1.708 municípios brasileiros com $20 \%$ de extrema pobreza ou mais da população vivendo em extrema pobreza, 1.393 municípios aderiram ao Programa, o equivalente a $82 \%$ de adesão. Tratase de fortalecimento de atenção a saúde da população que tinha dificuldade de acesso primário ao profissional médico. Em Santa Catarina, a porcentagem do aumento do número de médicos com o Programa Mais Médicos no período 2012-2015 (até junho de 2015), foi de 15,9\% ${ }^{11}$.

O Estado de Santa Catarina foi contemplado com a ampliação da formação e com a inclusão gradativa de novos médicos na Atenção Básica: estão em processo de criação dois novos cursos públicos em medicina através da Universidade Federal de Santa Catarina, polos nos municípios de Araranguá e Curitibanos, além de um curso de medicina privado no município de Jaraguá do Sul, pela Sociedade de Ensino Superior Estácio de Sá Ltda. e 199 municípios foram contemplados com médicos do Programa ${ }^{12}$.

Este artigo objetiva apresentar os aspectos históricos da criação do Programa Mais Médicos e um breve relato dos movimentos iniciais de uma pesquisa estadual em andamento, na perspectiva de um balizador pedagógico do Programa em Santa Catarina, entrevistado na qualidade de informantechave. Este breve relato de experiência faz parte da pesquisa em andamento intitulada "Impacto social do Programa Mais Médicos no Estado de Santa Catarina: realidades e perspectivas". 


\section{METODOLOGIA}

Estudo social, de abordagem mista e caráter exploratório, descritivo e compreensivo, aprovado pelo Comitê de Ética e em conformidade com as determinações da Resolução CNS 466/2012/ CNS/MS/CONEP. O desenho qualitativo do estudo considerou os seguintes objetivos específicos: a) reconhecer a dimensão ética e política desta iniciativa do governo federal, na perspectiva de balizadores pedagógicos do Programa em Santa Catarina; b) mapear os municípios catarinenses contemplados com o Programa; c) identificar e descrever as fortalezas e limites dos processos e fluxos de gestão do cuidado dos municípios catarinenses contemplados com o Programa, a partir de discursos dos gestores; d) identificar a dimensão ética e política na formação em medicina para a atenção básica, na visão dos balizadores pedagógicos do Programa em Santa Catarina; e) produzir uma tecnologia social, em formato CD-ROM, para os balizadores pedagógicos e Secretaria de Saúde do Estado de Santa Catarina; e f) produzir uma tecnologia de educação permanente para os gestores, de modo a enfrentar os prováveis limites e consolidar as prováveis fortalezas, identificados nos processos e fluxos de gestão do cuidado. Os instrumentos de coleta de dados eleitos no desenho qualitativo foram entrevista narrativa e semiestruturada, para os balizadores pedagógicos; e questionários e grupos focais para os gestores. No escopo deste artigo, estaremos relatando elementos da metodologia a ser utilizada com balizadores pedagógicos.

São considerados balizadores pedagógicos: os tutores do Programa no Estado; o consultor da Secretaria de Gestão do Trabalho e da Educação na Saúde (SGTES/MS), locado no Núcleo Estadual do Ministério da Saúde (NEMS) em Santa Catarina; o consultor da Diretoria de Desenvolvimento da Educação em Saúde (DDES/MEC) na Comissão de Coordenação Estadual (CCE) do Programa Mais Médico em Santa Catarina; o diretor da DDES/MEC e o Secretário da SGTES/MS.

A escolha por inserir um informante-chave no estudo se deu pela necessidade de os pesquisadores conhecerem os sujeitos institucionais pedagógicos no Estado: em que universidades eles estão locados; quem são; e que segmento do processo eles representam. Deste modo, o informante-chave foi eleito por intenção. O convite ao informante-chave foi realizado pessoalmente. A entrevista aconteceu na Universidade Federal de Santa Catarina, em agosto deste ano, e teve duração de duas horas e meia.

A entrevista narrativa constituiu-se de uma questão gerativa voltada para conhecer a história do Programa, da intenção ao gesto. Compreendendo a narrativa não como a tradução ipsis litteris da realidade vivenciada, mas como um processo dialético entre o discurso e a experiência, na medida em que a experiência gera o discurso, este também gera a experiência, ela acaba se constituindo na reinterpretação dos fatos pelo sujeito que os vivenciou ${ }^{16}$.

A entrevista semiestruturada foi composta por dois blocos. O primeiro agregou questões dirigidas para a busca por prováveis relações entre este Programa e a ESF, que valores foram realizados na construção da proposta, quais são os maiores desafios e potencialidades do Programa, como o 
Programa se relaciona com os entes federados; busca também a percepção sobre algumas notícias contrárias ao Programa, divulgadas por veículos midiáticos.

O segundo bloco de questões intenciona conhecer o papel do tutor no processo de interiorização de faculdades de medicina, se há supervisores in loco e como se dá o processo de trabalho destes, com os médicos e tutores; pretende também investigar se o Programa Mais Médicos retoma o ideário da conquista da VIII Conferência e, em que medida; investiga também a relação do Mais Médicos com iniciativas anteriores do governo federal relacionadas à formação da força de trabalho ideal para o SUS e como se pretende enfrentar a construção de quadro de docentes para os cursos de medicina de Araranguá e Curitibanos.

A categorização dos dados foi realizada a posteriori e a análise foi conduzida pela perspectiva hermenêutico-dialética.

\section{Breve relato sobre os movimentos iniciais do desenho qualitativo da pesquisa.}

Este estudo foi aprovação pela Fundação de Amparo à Pesquisa e Inovação do Estado de Santa Catarina (FAPESC), em janeiro de 2015. Após esta aprovação, o primeiro movimento consistiu em visitar a Secretaria Estadual de Saúde (SES/SC), em Florianópolis, para apresentar a pesquisa ao superintendente de planejamento e gestão. No encontro, fomos informados que deveríamos formalizar a pesquisa junto ao Coordenador Estadual do Programa de Provimento de Profissionais do Estado de Santa Catarina, na Escola de Saúde Pública. Dirigimos-nos para o referido local, mas não conseguimos contato com o Coordenador. $\mathrm{Na}$ ocasião, fomos recebidos por uma funcionária que nos sugeriu socializar a pesquisa ao Coordenador através de endereço eletrônico. Ela também nos apresentou a Composição de Coordenação Estadual (CCE) do Programa, em Santa Catarina, composto por: Coordenador; Ministério da Saúde; Conselho de Secretarias Municipais de Saúde de Santa Catarina (COSEMS); Universidade Federal de Santa Catarina (UFSC); Universidade Federal da Fronteira Sul (UFFS); Universidade Aberta do SUS; Gestão de Atenção Básica da SES/SC (GEABS); Programa de Valorização da Atenção Básica (PROVAB); e Programa Telessaúde.

O período compreendido entre março e maio do corrente ano correspondeu à fase de ajustamento do Projeto, na FAPESC. Paralelamente, fizemos uma pesquisa de reconhecimento na internet, através do site Portal da Saúde, do Ministério da Saúde, para identificar a Coordenação Nacional do Programa e constatamos que se tratava da SGTES/MS. Nesta busca, reconhecemos o consultor o da SGTES/MS no NEMS em Santa Catarina.

Em seguida, visitamos o site da Secretaria de Educação Superior (SESU) do MEC para conhecer a Coordenação Nacional do Programa. Observamos que esta coordenação estava sob a alçada da Diretoria de Desenvolvimento de Educação e Saúde (DDES). Nesta consulta, identificamos o consultor da DDES/MEC na Comissão Estadual do Programa Mais Médico em Santa Catarina.

Enquanto aguardávamos a apreciação do Projeto pelo Comitê de Ética, realizamos uma oficina 
com os pesquisadores integrantes da pesquisa, para fins de desdobramento do cronograma de execução e criação de uma agenda para reuniões mensais.

Em agosto, o projeto foi submetido ao Comitê de Ética. Após a apreciação e aprovação, deliberamos por iniciar a pesquisa qualitativa com os balizadores pedagógicos do Programa no Estado. Com base na entrevista realizada com o informante-chave, fizemos contato com a UFSC e com a UFFS para conhecer o quadro de tutores do Programa no Estado. Uma vez identificados, fizemos os convites para a participação no estudo.

Foram convidados os seguintes sujeitos: o representante da SGTES/MS no Núcleo Estadual do Ministério da Saúde (NEMS) em Santa Catarina; o representante da DDES/MEC na Comissão Estadual do Programa Mais Médico em Santa Catarina; e os quatro tutores do Programa no Estado de Santa Catarina ( considerando o informante-chave como o quinto tutor, sendo quatro deles vinculados à UFSC e o quinto locado na UFFS). Algumas entrevistas já foram realizadas, com registros em áudio e posterior transcrição.

A pesquisa com balizadores pedagógicos prevê, ainda, entrevistas com o Diretor da DDES/ MEC e com o Secretário da SGTES/MS. Ambos os convites serão realizados pessoalmente na ocasião do Seminário de Pesquisas Sobre o Programa Mais Médicos.

Neste relato de experiências iniciais, estaremos apresentando parte da narrativa coletada em entrevista com o informante-chave, eleito para orientar a construção do universo de sujeitos da pesquisa (balizadores pedagógicos). O texto apresentado a seguir é fruto da interação dialógica entre a narrativa do pesquisado e a compreensão do pesquisador ${ }^{16}$. As citações diretas do sujeito da pesquisa estão inseridas entre aspas. $\mathrm{O}$ anonimato do sujeito foi garantido pelo uso da sigla IC, representando a expressão "informante-chave". O texto foi conduzido pela categoria - Da intenção ao gesto: abraçando os inúmeros Brasis em defesa da garantia do direito universal à saúde.

\section{Da intenção ao gesto: abraçando os inúmeros Brasis em defesa da garantia do direito universal à saúde.}

O informante-chave inicia seu relato comentando sobre "uma reunião nacional de secretários municipais de saúde" (IC), ocorrida em 2012, na região nordeste, com o objetivo de informar à Presidente Dilma Roussef sobre a dificuldade de "montar a rede de atenção básica" (IC) na região. Secretários relataram que haviam aberto concursos, mas como "não tiveram médicos candidatos" (IC), o governo federal teria que criar uma estratégia de superação dessa realidade. "Ora, atrás dessa estratégia a ser montada [estava] uma falência de médicos de atenção básica; uma falência de modelo de formação" (IC).

Expressa, em sequência, que a VIII Conferência Nacional de Saúde havia defendido o modelo ampliado de saúde e que "uma de suas bandeiras era estruturar o sistema a partir da atenção básica" (IC). No entanto, a materialização dessa luta demorou um pouco para acontecer: da promulgação 
da Constituição até 1993 "pouco se fez" (IC). Em 1993, oportunizado por condições dadas, um grupo do Ministério da Saúde foi constituído para "ajudar a construir a proposta de PSF como uma extensão ampliada do PACS, implantado, em 1991, no governo Collor” (IC). O PACS, mantendose vigente no governo de Itamar Franco, foi investido para ser transformado em Programa de Saúde Comunitária (PSC). No entanto, o Fundo das Nações Unidas para a Infância (UNICEF) não concordando com esta denominação, acabou influenciando a decisão brasileira na escolha do nome: da ideia do Programa de Saúde Comunitária surgiu o Programa Saúde da Família.

A partir da criação do PSF, provavelmente o nome do Programa começou a mobilizar a Sociedade Brasileira de Medicina Comunitária (SBMFC), pois, segundo o informante-chave a SBMFC "resolveu mudar de nome para aproveitar o mote do Ministério" (IC), passando a chamarse, em 2001, Medicina de Família e Comunidade. A partir da Lei do Mais Médicos a especialidade passou a chamar-se "Medicina Geral de Família e Comunidade". Pode ser melhor detalhada na Resolução $n^{\circ}$ 1, de 25 de maio de 2015, da Secretaria de Educação Superior. Considerando a Medicina Geral de Família e Comunidade como a especialidade médica que engloba a prestação de cuidados personalizados e continuados a indivíduos e famílias de uma determinada população, independentemente de idade, sexo ou problema de saúde ${ }^{17}$.

O PSF “entrou em vigor em 1994, no governo de Fernando Henrique Cardoso [mas até] 1997 não teve financiamento" (IC). Em 1997, "o Programa começa com verba ministerial vinda do Banco Mundial, o que era uma contradição porque a gente queria que fosse atenção básica brasileira" (IC). O Banco Mundial, por sua vez, "deu uma distorcida imensa no Programa, fez restrições" (IC) e também exigências, por exemplo, que cada equipe do Programa fosse responsável "por mil famílias, e a gente queria que fosse no máximo duas mil pessoas" (IC).

Ainda assim, em 1997 o PSF "começa de fato a ter expansão, a ter financiamento" (IC). Interconectado a este movimento, "as Residências em Medicina Geral e Comunitária se transformam em Residências de Medicina de Família” (IC). Há um "boomzinho, entre 1997 e 2003/2004, quer dizer, do final do governo de FHC e início do governo Lula" (IC). Em seguida, o Programa estabiliza-se com aproximadamente " 15 mil equipes, áreas construídas [...] a rede aumentando sem médicos, ausência de médicos nas periferias das cidades grandes, no interior do Brasil ninguém mesmo" (IC).

Em 2004, o Grupo Gestor do Programa "encaminhou um Plano de Carreira ao Ministério, o Ministério encaminhou para a Câmara e Senado [...] faz 11 anos que o plano está lá e não aprovam" (IC). Várias iniciativas foram criadas pelo governo federal, voltadas para, dentre outras, a formação da força de trabalho ideal para o SUS tais como: Programa de Valorização do Profissional da Atenção Básica (PROVAB), Programa Nacional de Reorientação da Formação Profissional em Saúde (PRÓ-SAÚDE), Programa de Educação pelo Trabalho para a Saúde (PET-SAUDE), PROMED, Residências multiprofissionais e médicas. Essas tentativas universitárias buscavam "a sensibilização na formação, mas sensibiliza pouco, $5 \%$ de uma turma é o que sensibiliza, e isso não 
cobre a necessidade brasileira" (IC).

Passados mais de dez anos, especificamente em junho de 2013, o Brasil despertou com manifestações de rua "pedindo mais saúde para o país" (IC). No segundo semestre, a partir do acordo de cooperação internacional entre Brasil e Cuba, mediado pela Organização Pan-Americana da Saúde (OPAS/OMS), o país começava a receber médicos cubanos. Diferentemente dos demais médicos que vieram pelo Programa Mais Médicos, para trabalhar na lógica de disputa de mercado, os médicos cubanos concordaram em vir trabalhar em missão internacional, por um salário bem menor que os demais médicos (brasileiros e intercambistas). "Do salário de $\mathrm{R} \$ 10.000$ reais, pagos pela OPAS, 70\% ficam em Cuba, 30\% ficam com o médico cubano, mais a garantia de casa e comida [...] eles estão felizes em princípio com [o fato de 70\%] ficar em Cuba porque está ajudando o país deles e suas famílias estão se beneficiando com isto" (IC).

Com a chegada de médicos cubanos, o Grupo de Trabalho (GT) Mais Médicos federal "volta a se reunir em Brasília e monta uma comissão pedagógica para ajudar a organizar a estrutura da supervisão desses médicos, articulando a proposta de tutoria, supervisão [...] ao final de 2013, começa-se a nomear tutores [...] tutores começam a escolher supervisores [conforme aumenta o número de médicos cubanos] começa a aumentar o número de supervisores. "Municípios começam a se mobilizar pedindo o Mais Médicos, chegam novos médicos, a gente reivindica mais um tutor" (IC).

Quando o GT se reuniu em Brasília para discutir a comissão pedagógica, o mapa do Programa mostrava "oito mil unidades construídas sem médico [...] 600 barcos na Amazônia para atender a população ribeirinha, equipados com equipamentos de ponta, sem médico" (IC). Ofereceu-se "para os brasileiros, nenhum quis, para os estrangeiros nenhum quis, para os cubanos [...] vão aonde a gente mandar" (IC). Ao contrário de cubanos, "os médicos de outros países vieram em busca de mercado de trabalho no litoral, lidam com equipamentos como os brasileiros acostumaram a lidar [já os cubanos] vêm fazer uma missão internacional a um país vizinho [sobre estes] não temos tido reclamação de quase nenhum, eles têm excelência em atenção básica, em condições precárias, eles têm uma excelência absolutamente mundial, OMS diz isso" (IC).

"O grande problema é que os cubanos estão vindo provisoriamente [...] quando eles forem embora quem é que fica? Então, nós temos que formar um outro jeito de formar médicos. Abrir faculdade no interiorzão [...] 'ahhh, mas não tem professor'; nós vamos inventar professor” (IC).

Deste modo, aqui em Santa Catarina "a gente tem essa dupla militância" (IC): tutoria e organização de novos cursos de graduação em medicina. "Araranguá não tem médicos de atenção básica, os nossos supervisores estão sendo capacitados para serem prováveis professores. Foi-nos dado: contratem 60 professores. Como é que a gente vai montar uma faculdade com 60 professores? Bom, anatomia não vai ter um professor específico, vai ter um médico de família que vai ensinar anatomia; eles sabem anatomia? Sabem a anatomia necessária para exercer a medicina de família. 
Isso é uma experiência importantíssima [...] estão sendo montadas no Nordeste, no interior da Amazônia [...] a ideia é: na medida em que a gente conseguir mudar o ingresso, este já se fixe lá [...] e como ele já é de lá... (IC).

Importante relatar que depois de formado "o médico só vai poder atender se tiver residência, e para ter residência as faculdades de medicina terão que abrir no primeiro ano residência em medicina de família, urgência e emergência e saúde mental que são as três áreas que mais faltam no país [...] depois vão ter que manter a medicina de família, as outras duas elas abrem no que quiserem" (IC).

"A gente tem também uma discussão severa em termos de plano de carreira, para que a gente coloque como primeiro patamar de plano de carreira, isso que está acontecendo com o Mais Médicos: o cara trabalha dois, três anos, e é promovido para capital do estado onde ele está trabalhando; três anos depois ele pode escolher a cidade que ele quiser [...] isso está em discussão, é um trunfo super importante porque todo mundo passaria um bom tempo trabalhando na atenção básica; isso melhora a atenção básica e não tem sido enfatizado nos cursos" (IC) [tradicionais].

Além disto, "consolidaria as faculdades de medicina e garantiríamos o financiamento para novas faculdades de medicina, em rincões distantes do país; para que a gente consiga aprovar faculdades de medicina em rincões distantes, precisaríamos de uma legislação especial do MEC que permitisse salários diferenciados para professores dessas universidades. Veja, tu tens um salário de professor universitário de federal de $\mathrm{R} \$ 8.000,00$ reais por mês, tu entras na faculdade, tu entras para dar aula, a R\$6.000,00 e pouco por mês [livre], aí abre uma faculdade de medicina em Tabatinga, interior do Amazonas, precisamos de professores para dar aula, quem vai? Quem são os 60 professores que vão receber $\mathrm{R} \$ 6.000,00$ por mês para dar aula lá? Vamos ter que resolver isto, com legislação especial para que médicos de família possam dar aula em universidades federais com um programa de mestrado específico para eles: enquanto estão sendo professores eles se capacitam como mestres em três anos. A segunda coisa é garantir que esses médicos de família recebam duplo salário, que eles sejam os médicos da rede ganhando $\mathrm{R} \$ 10.000,00$ na rede, e os $\mathrm{R} \$ 6.000,00$ na universidade; [assim,] talvez a gente conseguisse fazer faculdade em Tabatinga" (IC).

"Com plano de carreira, residência, modelo formativo, novas faculdades e médicos intercambistas a gente espera recuperar a estruturação do SUS. A gente tem clareza de que aonde está acontecendo o Mais Médicos, a população está sendo atendida da forma como a gente defende no modelo de Reforma Sanitária, de uma forma humanizada, [com a] clínica ampliada, [com o] médico próximo da população" (IC).

\section{CONSIDERAÇÕES FINAIS}

O reconhecimento intransigente da conquista e da garantia do SUS exige a materialização de políticas inclusivas, ancoradas no imperativo ético de garantir a todos brasileiros a realização do 
direito à saúde. Idos 27 anos de existência de um Sistema de Saúde público como direito de todos, democrático e aberto ao diálogo, várias iniciativas do Estado brasileiro geraram avanços no processo de consolidação desta conquista. No âmbito do cuidado integral, campo do fazer na realidade cotidiana $^{18}$, o Programa Saúde da Família e a Estratégia Saúde da Família, priorizada pela Política Nacional de Atenção Básica como gestora das necessidades de saúde da população, representaram um avanço indiscutível, tanto em áreas desenvolvidas como em rincões marginalizados.

No entanto, diferentemente dos Brasis "luminosos", os Brasis "opacos"19 ainda clamam por políticas/programas inclusivos suficientemente capazes de garantir o acesso ao cuidado e a sua continuidade. Estes Brasis ainda clamam pela ampliação da atenção aos seus cidadãos, aqueles que vivem às margens ou mesmo negligenciados, em seu direito de realizar saúde.

Após atenta leitura à narrativa do informante-chave sobre a história do Programa Mais Médicos, observou-se que o Programa representa uma franca possibilidade de garantia de realização do direito à saúde em rincões sombrios, marginalizados pela ausência de médicos, bem como um projeto transformador efetivo em defesa de uma formação em medicina para a Atenção Básica, para o SUS de todos os brasileiros: a serviço do Brasil.

O Programa Mais Médicos foi e segue sendo uma iniciativa com muitos desafios. Isto é fato. Primeiramente, pela amplitude e complexidade das intervenções almejadas. Simultaneamente, pela presença necessária e transformadora da realidade do acesso à saúde no Brasil, de modo integral. Por induzir e prover assistência aos cuidados médicos em lugares com ausência ou baixa cobertura, além de construir uma proposta de regionalização da formação médica em municípios fora dos grandes eixos populacionais, o Programa tem produzido mudanças no acesso à população ao trabalhador médico.

Os aspectos relatados pelo informante-chave sobre a história do Programa reacendem a esperança de que todos os Brasis possam, um dia, ter acesso a cuidados médicos na Atenção Básica: um direito social. $\mathrm{O}$ mergulho na narrativa remeteu a um poeta brasileiro que retratou com maestria a associação entre carência de direitos sociais e opacos "Brasis"19: Fernando Brandt. Em uma linguagem ética de reconhecimento dos mais variados "Brasis", Brandt deixou um rico legado ao povo brasileiro. Transitando do Brasil sofrido e marginalizado ao Brasil que resiste e sonha um vir a ser, o poeta cristalizou o sonho de sonhar um Brasil para todos, em Coração civil: "Se o poeta é o que sonha o que vai ser real/Vou sonhar coisas boas que o homem faz/ E esperar pelos frutos no quintal".

\section{REFERÊNCIAS BIBLIOGRÁFICAS}

1. Lima RCGS, Severo DO, Verdi MIM, Da Ros MA. A construção do direito à saúde na Itália e no Brasil na perspectiva da bioética cotidiana. Saude soc. 2009 Jan./Mar. 18(1): 188-30.

2. Viana ALA, Dal Poz MR. Reforma do Sistema de Saúde no Brasil e o Programa Saúde da 
Família. PHYSIS: Rev. Saúde Coletiva. 2005 Nov./Dez. 8(2): 11:48.

3. Ministério da Saúde (BR). Portaria n 2.488, de 21 de outubro de 2011: aprova a Política Nacional de Atenção Básica, estabelecendo a revisão de diretrizes e normas para a organização da Atenção Básica, para a Estratégia Saúde da Família (ESF) e o Programa de Agentes Comunitários de Saúde (PACS). Diário Oficial [da] Republica Federativa do Brasil. Brasília, DF, 24 out. 2011; Seção 1, p. 51.

4. Temporão JG. Saúde da Família, agora mais do que nunca! Ciência \& Saúde coletiva. 2009 sept./Oct. 14(supl. 1): 1493:97.

5. Ministério da Saúde (BR). Portaria nº 648/GM, de 28 de março de 2006. Aprova a Política Nacional de Atenção Básica, estabelecendo a revisão de diretrizes e normas para a organização da Atenção Básica para o Programa Saúde da Família (PSF) e o Programa Agentes Comunitários de Saúde (PACS). Política Nacional de Atenção Básica Portaria No 648.

6. Ney MS, Rodrigues PHA. Fatores críticos para a fixação do médico na Estratégia Saúde da Família. Physis. 2012 Nov./Dez. 22(4): 1293-1311.

7. Ceccim RB. Onde se lê recursos humanos da saúde, leia-se coletivos organizados de produção da saúde: desafios para a educação. In: Pinheiro R, Mattos R. (Orgs.). Construção social da demanda: direito à saúde, trabalho em equipe, participação e espaços públicos. Cepesc. Rio de Janeiro. 2005. p.161-80.

8. Carvalho MS, Sousa MF. Como o Brasil tem enfrentado o tema provimento de médicos? Interface (Botucatu). 2013 Out./Dez. 17(47): 913-26.

9. Campos CVA, Malik AM. Satisfação no trabalho e rotatividade dos médicos do Programa de Saúde da Família. Rev. Adm. Publica. 2008 Mar./Abr. 42(2):347-68.

10. Capozzolo AA. No olho do furacão: trabalho médico e o Programa de Saúde da Família [Tese]. Campinas: Universidade Estadual de Campinas, Faculdade de Ciências Médicas; 2003.

11. Ministério da Saúde (BR). Secretaria de Gestão do Trabalho e da Educação na Saúde. Programa Mais Médicos - dois anos: mais saúde para os brasileiros. Brasília: Ministério da Saúde, 2015.

12. Ministério da Saúde (BR). Lei n. 12.871, de 22 de outubro de 2013. Institui o Programa Mais Médicos, altera as Leis no 8.745, de 9 de dezembro de 1993, e ํㅜ 6.932, de 7 de julho de 1981, e dá outras providências. Diário Oficial [da] Republica Federativa do Brasil. 2013 out. 23; Seção 1, p. 1.

13. Oliveira FP, Vanni T, Pinto HA, et al. Mais Médicos: um programa brasileiro em uma 
perspectiva internacional. Interface (Botucatu) [online]. 2015 set. 19(54): 623-34.

14. Ministério da Saúde (BR). Portaria Interministerial no 1.369, de 8 de julho de 2013. Dispõe sobre a implementação do Projeto Mais Médicos para o Brasil. Diário Oficial [da] República Federativa do Brasil. 2013 jul. 9; Seção 1, p.49-52.

15. IBGE. Cidades [dados na Internet] Rio de Janeiro: IBGE [acesso em 27 set. 2015]. Disponível em http://www.ibge.gov.br

16. Cunha MI. Conta-me agora!: as narrativas como alternativas pedagógicas na pesquisa e no ensino. Rev. Fac. Educ. 1997 Jan./Dec. 23(1-2): 185-95.

17. Ministério da Educação (BR). Secretaria de Educação Superior. Resolução No 1, de 25 de Maio de 2015. Regulamenta os requisitos mínimos dos programas de residência médica em Medicina Geral de Família e Comunidade - R1 e R2 e dá outras providências. Brasília: Ministério da Saúde, 2015.

18. Bordieu P. A economia das trocas linguísticas. São Paulo: Edusp; 1996.

19. Santos M, Silveira ML. O Brasil: Território e Sociedade no início do século XXI. Rio de Janeiro: Editora Record; 2001.

Artigo apresentado em 05-08-15 Artigo aprovado em 21-11-15 Artigo publicado no sistema em 30-12-15 